Published in final edited form as:

Sci Transl Med. 2016 May 11; 8(338): 338ra67. doi:10.1126/scitranslmed.aaf3006.

\title{
Delayed globin synthesis leads to excess heme and the macrocytic anemia of Diamond Blackfan anemia and del(5q) myelodysplastic syndrome
}

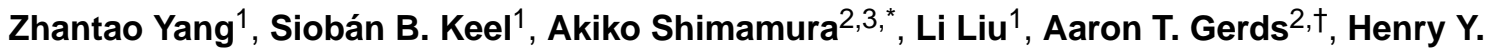 \\ $\mathrm{Li}^{4}$, Brent L. Wood ${ }^{1}$, Bart L. Scott ${ }^{2}$, and Janis L. Abkowitz ${ }^{1, \neq}$ \\ ${ }^{1}$ University of Washington, Seattle, WA 98195, USA \\ ${ }^{2}$ Fred Hutchinson Cancer Research Center, Seattle, WA 98109, USA \\ ${ }^{3}$ Seattle Children's Hospital, Seattle, WA 98105, USA \\ ${ }^{4}$ Polyclinic, Seattle, WA 98104, USA
}

\begin{abstract}
Diamond Blackfan anemia (DBA) and myelodysplastic syndrome (MDS) with isolated del(5q) are severe macrocytic anemias; although both are associated with impaired ribosome assembly, why the anemia occurs is not known. We cultured marrow cells from DBA $(n=3)$ and del $(5 q)$ MDS $(n$ $=6$ ) patients and determined how heme (a toxic chemical) and globin (a protein) are coordinated. We show that globin translation initiates slowly, whereas heme synthesis proceeds normally. This results in insufficient globin protein, excess heme and excess reactive oxygen species in early erythroid precursors, and CFU-E (colony-forming unit-erythroid)/proerythroblast cell death. The cells that can more rapidly and effectively export heme or can slow heme synthesis preferentially survive and appropriately mature. Consistent with these observations, treatment with $10 \mathrm{mM}$
\end{abstract}

\footnotetext{
${ }^{\ddagger}$ Corresponding author. janabk@uw.edu.

*Present address: Boston Children's Hospital, Boston, MA 02115, USA.

$\dagger$ Present address: Cleveland Clinic, Cleveland, OH 44195, USA.
}

Author contributions: Z.Y., S.B.K., L.L., and B.L.W. performed the experiments; S.B.K., A.S., A.T.G., H.Y.L., B.L.S., and J.L.A. provided patient marrows and clinical data; and Z.Y. and J.L.A. wrote the article, which was reviewed and edited by the other authors.

Competing interests: The authors declare that they have no competing interests.

SUPPLEMENTARY MATERIALS

www.sciencetranslationalmedicine.org/cgi/content/full/8/338/338ra67/DC1

Patient information

Fig. S1. The in vitro erythroid differentiation of normal human BMMNCs mimics in vivo differentiation.

Fig. S2. Heme availability is highest in early erythroid cells.

Fig. S3. Preferential selection during erythropoiesis.

Fig. S4. Sequential assessment of mRNA in marrow cultures from DBA patient 1 and del(5q) MDS patient 6.

Fig. S5. Hemopexin facilitates heme export through FLVCR to improve the erythroid differentiation of DBA patient 1's marrow cells.

Fig. S6. Studies of MDS patients with RARS and RCMD.

Fig. S7. P53 activation, heme excess, and ferroptosis.

Fig. S8. Isotype controls and gating strategy for flow cytometry.

Fig. S9. Unmodified complete Western blots.

Table S1. Clinical data from the MDS patients.

Table S2. Probe and primer set for quantitative real-time PCR

Table S3. Source data and statistical calculations for Fig. 3.

Table S4. Source data and statistical calculations for Fig. 4.

Reference (48) 
succinylacetone, a specific inhibitor of heme synthesis, improved the erythroid cell output of DBA and del(5q) MDS marrow cultures by 68 to $95 \%$ ( $P=0.03$ to 0.05 ), whereas the erythroid cell output of concurrent control marrow cultures decreased by 4 to $13 \%$. Our studies demonstrate that erythropoiesis fails when heme exceeds globin. Our data further suggest that therapies that decrease heme synthesis (or facilitate heme export) could improve the red blood cell production of persons with DBA, del(5q) MDS, and perhaps other macrocytic anemias.

\section{INTRODUCTION}

Diamond Blackfan anemia (DBA) is a dominantly inherited macrocytic anemia, often associated with congenital anomalies. Twenty-five percent of cases result from haploinsufficiency of ribosomal protein S19 (RPS19), and 30\% result from haploinsufficiencies of 10 other ribosomal proteins (1). When tested, these mutations disrupt ribosome assembly and impair the translation of mRNA to protein (2). How this causes erythroid marrow failure, and specifically macrocytic anemia, remains uncertain. A dominant theory is that there is a relative excess of specific ribosomal proteins, P53 pathway activation, and cell apoptosis (3-6). However, why erythropoiesis is severely affected, whereas other lineages, such as granulocytes and lymphocytes, as well as nonhematopoietic cells, function appropriately, is difficult to reconcile with this hypothesis. Others hypothesize that there is aberrant splicing or abnormal translation of select mRNAs (7-9).

The myelodysplastic syndrome (MDS) associated with isolated del(5q), an acquired macrocytic anemia characterized by reticulocytopenia and low risk of leukemia evolution, is also associated with the haploinsufficiency of a ribosomal protein, specifically RPS14, and poor ribosome assembly $(10,11)$.

These observations led us to predict that DBA and del(5q) MDS share a pathogenesis that reflects the very rapid kinetics of red blood cell and hemoglobin production, and specifically that poor ribosome assembly leads to delayed protein (thus, globin) translation in early erythroid precursors and excess heme. Because free heme is toxic, cell death ensues.

Erythroid differentiation is diagrammed in Fig. 1A. Under the influence of erythropoietin, early erythroid precursors [CFU-E (colony-forming units-erythroid)/proerythroblasts] upregulate transferrin receptor 1 (TfR1, CD71) $(12,13)$ and import iron. Iron induces $\delta$ aminolevulinate synthase 2 (ALAS2), an erythroid cell-specific enzyme, which catalyzes the first and rate-limiting step of heme synthesis (14). Heme then rapidly induces globin transcription and translation, by inhibiting repressors BACH1 $(15,16)$ and heme-regulated eIF2a (eukaryotic initiation factor $2 a$ ) kinase (HRI) (17), respectively. This mechanism assures that globin is briskly synthesized as soon as heme is available, and only when heme is available.

Erythroid cells, however, take several risks to guarantee that adequate heme persists and thus are vulnerable to heme toxicity. ALAS2 (in contrast to ALAS1, the isoform of nonerythroid cells) is not subject to feedback inhibition by heme $(18,19)$. Therefore, heme synthesis continues as long as iron is available without an intrinsic brake. In nonerythroid cells, excess heme transcriptionally up-regulates heme oxygenase-1 (HMOX1), which degrades heme 
into elemental iron, carbon monoxide, and biliverdin. However, if early erythroid cells metabolized heme through HMOX1, this could result in inadequate heme once globin was available and dampen red blood cell production. Therefore, CFU-E and proerythroblasts depend on feline leukemia virus subgroup C (FeLV-C) receptor (FLVCR), a cytoplasmic heme exporter, during that short interval during early erythroid differentiation when heme is in excess of globin production (Fig. 1A, gray bar) $(20,21)$.

That FLVCR and heme export are essential for effective red blood cell production has been demonstrated in studies of cats and mice. When cats are viremic with FeLV-C, the cell surface expression of FLVCR is inhibited by retroviral interference. This leads to CFU-E/ proerythroblast arrest and a marrow morphology and clinical findings resembling DBA and del(5q) MDS $(22,23)$. Similarly, deletion of FLVCR in neonatal or adult mice causes CFUE/proerythroblast cell death and progressive macrocytic anemia (20). CFU-E and proerythroblasts from FLVCR-deleted mice contain high levels of heme and increased cytoplasmic (but normal levels of mitochondrial) reactive oxygen species (ROS) (24), suggesting that some cell death results from ferroptosis (25-27), a newly described ROSdependent cell death pathway. Limiting heme synthesis by dietary iron restriction or genetic approaches improves the macrocytosis and the anemia (24), implying that heme excess causes, and is not just associated with, the erythroid marrow failure.

These observations led us to predict that the macrocytic anemia of DBA and del(5q) MDS would have a similar pathophysiology to the macrocytic anemia of FeLV-C viremic cats and FLVCR-deleted mice. Should globin synthesis initiate slowly, heme excess would extend for a longer period of time (Fig. 1A, longer gray bar), and heme export through FLVCR, although intense, could be insufficient.

Here, we validate this hypothesis by studying marrow cells from patients with DBA and $\operatorname{del}(5 q)$ MDS. We show that translation is impaired and globin production is delayed, resulting in excess heme, excess cytoplasmic ROS, and CFU-E/proerythroblast cell death. Erythropoiesis improves when heme synthesis is reduced or heme export is increased so that heme and globin better coordinate, suggesting that this could be an efficacious therapy for these disorders. Because more than $95 \%$ of the protein content of red blood cells is hemoglobin, any mutation or event that ubiquitously impedes protein transcription or translation could delay globin up-regulation and result in excessive heme. Therefore, decreasing heme synthesis might also help other individuals with macrocytic anemia, including MDS patients without del(5q).

\section{RESULTS}

\section{In DBA, erythropoiesis fails at or just before the proerythroblast stage}

Figure 1B shows a detailed flow cytometric assessment of marrow from DBA patient 1, a 28-year-old female with RPS19 haploinsufficiency who is transfusion-dependent. A high percentage of her CD34-positive marrow cells are CD38-low and thus very early progenitors, and the few CD71-positive cells that are present are proerythroblasts, as noted by their coexpression of CD117 (c-kit). These direct patient data suggest that DBA erythroid cells die at or just before the proerythroblast stage, when they first express the TfR, import 
iron, and begin heme synthesis. To better characterize this defect and study its relationship to heme and globin synthesis, we cultured marrow cells from normal individuals $(n=5)$, DBA patients $(n=3)$, MDS patients with del $(5 q)(n=6)$, and relevant controls $(n=5)$.

\section{The coordination of heme with globin synthesis during normal in vitro erythropoiesis} parallels normal in vivo erythropoiesis

The time-wise coordination of heme synthesis, globin synthesis, and other molecular and cellular events controlling erythropoiesis is best assessed by observing events longitudinally as cells differentiate and mature in vitro. Therefore, we optimized the three-step culture approach of Giarratana et al. (28), confirmed that normal marrow progenitor cells appropriately differentiate and fully hemoglobinize by days 13 to 17 (fig. S1A), determined that ample erythroid cells were present at each stage (I to IV) of differentiation at culture day 10 to sort by flow cytometry for stage-specific assays, and, in preliminary studies, demonstrated that heme synthesis (assayed by $A L A S 2$ and total cellular heme content) intensifies before $\alpha$-globin or $\beta$-globin synthesis [assayed by reverse transcription polymerase chain reaction (RT-PCR) and Western blot analyses] (fig. S1B). As predicted, cells in stages I $\left[\mathrm{CD} 71^{+} \mathrm{CD} 36^{-} \mathrm{GlyA}^{-}\right.$cells; BFU-E (burst-forming unit-erythroid) and early CFU-E (13)] and II [CD71 ${ }^{+} \mathrm{CD} 36^{+} \mathrm{GlyA}^{-}$cells; CFU-E/early pro-erythroblast (13)] lack HMOX1, which degrades heme (fig. S1B). In addition and consistent with these findings, the expression of FLVCR is high in early erythroid cells, but decreases as cells mature to stages III $\left(\mathrm{CD}^{2} 6^{+} \mathrm{GlyA}^{+}\right)$and IV $\left(\mathrm{CD}^{-} 6^{-} \mathrm{GlyA}^{+}\right)$and heme and globin production becomes sufficiently matched (fig. S1B). Thus, normal erythropoiesis in vitro proceeds similarly to normal erythropoiesis in vivo.

To directly assess heme availability as erythroid cells mature, we used a heme-responsive luciferase assay and measured the amount of heme that is available to transcriptionally upregulate globin (fig. S2). As anticipated, heme-dependent BACH1 derepression of the $\beta$ globin promoter is also highest during early erythroid differentiation.

\section{In cultures of DBA marrow, erythropoiesis fails at or just before the proerythroblast stage, as in vivo}

We next cultured marrow cells from DBA patients and observed that their erythroid differentiation differed from control cultures. As shown in Fig. 2, the relative (Fig. 2A) and absolute (Fig. 2B) numbers of DBA cells decrease between stages I and II, whereas cell numbers progressively increase in control cultures.

\section{In patients with DBA, globin synthesis initiates slowly}

Figure 2 also shows heme and globin measurements. Heme synthesis begins normally in the DBA cells (as measured by the transcriptional up-regulation of ALAS2; Fig. 2C), and the heme content of stage I DBA cells is high (Fig. 2D). However, the a-globin and $\beta$-globin protein levels are below detection even in stages III and IV, whereas globin protein is easily visualized in the concurrent normal marrow culture by these stages of erythroid differentiation (Fig. 2E). Thus, heme is high and globin is low or absent at the time when erythroid differentiation fails. 
a-Globin and $\beta$-globin mRNA levels are also lower in the DBA cells than in the control cells (Fig. 2, F and G), but the reduction is less extensive than the reduction in globin protein that was measured simultaneously. We suspect that the decrease in a-globin and $\beta$-globin mRNA reflects the degradation of mRNA that is unable to bind ribosomes, given the limited ribosome number or availability. Together, these data support the concept that ribosomal protein deficiency and poor ribosome assembly lead to insufficient globin translation and excessive heme.

Figure 3 shows cumulative data from the three DBA patients and confirms these observations. Cell expansion is lower than controls ( $n=3 ; P=0.009, t$ test) (Fig. 3A), and stage I cells have an increased heme content ( $n=3 ; P=0.036, t$ test) (Fig. 3B).

\section{DBA cells able to limit heme preferentially survive}

Although the number of DBA cells falls between stages I and II, the few DBA cells that persist in stage II expand in number when differentiating to stages III and IV (Fig. 2B). Thus, it appears that the DBA cells, which are able to survive and proceed to stage II, can normally complete their erythroid differentiation. Noting this, we compared stage III and IV DBA cells (that is, GlyA ${ }^{+}$DBA cells) to stage III and IV cells in the concurrent control cultures at culture day 10 with the intent of defining those characteristics that allowed the DBA cells to preferentially survive and mature.

Stage III and IV DBA cells expressed 2.4-fold less $A L A S 2$ ( $n=3 ; P=0.031, t$ test) and 2fold more $F L V C R$ mRNA than stage III and IV control cells ( $n=3 ; P=0.044, t$ test) (Fig. 3, $\mathrm{C}$ and D). Because the expression of $A L A S 2$ and $F L V C R$ is not significantly different between DBA and control cells $\left(2.53 \pm 0.72\right.$ versus $3.61 \times 10^{4} \pm 0.93 \times 10^{4}$ copies and 3.67 \pm 0.10 versus $2.73 \times 10^{3} \pm 0.57 \times 10^{3}$ copies, respectively; $n=3 ; P=0.29, t$ tests) in stage I (the stage when heme synthesis initiates but cell death has not yet occurred), these data imply that DBA cells with higher heme synthesis or less heme export die and DBA cells with lower heme synthesis or higher heme export survive (fig. S3).

\section{Studies of sequentially sampled cultures confirm these results}

Flow cytometric sorting can present a bias if a cell's surface antigen display is not entirely concordant with its differentiation state. Therefore, we sought a second, independent method to confirm our results and sequentially sampled DBA patient 1 and control cultures at days 3, 7, 10 (step 1), 13 (step 2), and 17 (step 3); tracked differentiation within the (nonsynchronized) maturing cell population (Fig. 4A); and directly assessed the time-wise coordination of heme synthesis with globin synthesis. This is a useful approach as ALAS2 and globin are expressed in erythroid marrow cells, but not in other marrow cells. The levels of $A L A S 2$ mRNA are similar in the DBA and concurrent control cultures at day 3 (fig.

S4A), and ALAS2 protein is actually higher in the DBA culture (Fig. 4, B and C) at day 3. Thus, heme synthesis initiates quickly and proceeds normally. However, as shown in Fig. 4(B and C), globin synthesis is delayed. Globin protein is just beginning to increase at day 10 in the DBA culture, whereas it is abundant in the control culture at this time. During the time that heme is high and globin is low, there is excess cytoplasmic ROS and excess erythroid cell death. At culture day 7, high numbers of DBA cells (62.8\% versus $44.7 \%$ ) 
contained cytoplasmic ROS [mean fluorescence intensity (MFI), 1.42× control], although the MFI of mitochondrial ROS was equivalent ( $0.96 \times$ control) (Fig. 4D). As expected, 19.4 and $14.8 \%$ of cells in DBA culture stained positively for annexin $\mathrm{V}$ and propidium iodide (versus 12.1 and $6.1 \%$ in the control culture, respectively) (Fig. 4E).

Consistent with these findings, inhibiting heme synthesis with $10 \mu \mathrm{M}$ succinylacetone improved the erythroid differentiation of DBA marrow cells but impaired the erythroid differentiation of control cells (Fig. 4F). Succinylacetone is potent and specific inhibitor of the second step of the heme synthetic pathway (29). Similarly, facilitating heme export through FLVCR by adding hemopexin $(1.5 \mu \mathrm{M})(30)$ at culture day 2 improved the erythroid differentiation of DBA marrow cells but did not affect the erythroid differentiation of normal cells (Fig. 4G and fig. S5). Heme export through FLVCR requires a heme-binding protein external to the cell, and export speed and extent depend on this protein's concentration and affinity for heme. Hemopexin [dissociation constant $\left(K_{\mathrm{d}}\right)<1 \mathrm{pM}$ ] is 100 -fold more efficient in promoting heme export through FLVCR than is an equimolar concentration of albumin $\left(K_{\mathrm{d}}=5 \mathrm{nM}\right)$. Thus, either decreasing heme synthesis (with succinylacetone) or increasing heme export (with hemopexin) improves DBA erythropoiesis.

\section{The ineffective erythropoiesis of the del(5q) MDS also reflects heme toxicity}

Figure 3 also shows the cumulative data from five MDS patients with del(5q). Cells were studied at day 10 of culture, and the findings are similar to DBA. Erythroid differentiation fails between stages I and II; stage I cells have excess heme (Fig. 3B); and those cells able to survive, hemoglobinize, and mature to stages III and IV have 2.9-fold less $A L A S 2$ ( $n=5 ; P$ $=0.037, t$ test $)$ and 9.4-fold higher FLVCR $(n=5 ; P=0.002, t$ test $)$ mRNA than control cells (Fig. 3, C and D), suggesting that cells able to down-regulate their heme content preferentially survive and appropriately mature.

In studies of the sixth del(5q) MDS patient, the culture was sequentially sampled (Fig. 4H) and results also resemble DBA. Heme synthesis (ALAS2 mRNA and protein) progresses normally, but globin production is delayed (Fig. 4, I and J, and fig. S4B). In addition, at day 7 , increased numbers of del(5q) MDS cells have cytoplasmic ROS (74.1\% versus $44.7 \%$ in the concurrent control culture; MFI, 3.54× control) (Fig. 4D). Increased numbers of cells also stain positively for annexin $\mathrm{V}(19.8 \%$ versus $5.3 \%)$ and propidium iodide (13.6\% versus $1.1 \%$ ) (Fig. 4E). Furthermore, treatment with succinylacetone or hemopexin improves erythroid differentiation (Fig. 4, F and G).

As additional controls and to ensure the specificity of the cell culture results, marrow was obtained from an MDS patient with refractory anemia with ring sideroblasts (RARS) and an MDS patient with refractory cytopenia with multilineage dysplasia (RCMD). Neither had cytogenetic or interphase fluorescence in situ hybridization abnormalities. Cell expansion was diminished (after 17 days, cell numbers increased 6.12- and 2.79-fold versus 27.7- and 22.6-fold in the concurrent control cultures) as expected. Also, more cells were present in stage I (56.6 and $75.8 \%)$ at culture day 10 and fewer in stage II (20.8 and 10.2\%), so the block in erythroid differentiation appeared similar (fig. S6). In the RCMD patient culture, the heme content of stage I cells was normal; however, the heme content of RARS stage I cells was significantly lower than in normal subjects $(0.95 \pm 0.05$ versus $4.01 \pm 0.37 \mathrm{ng}$ per 
$10^{4}$ cells; $n=2 ; P=0.002, t$ test), as anticipated, given that the presence of RARS (excess mitochondrial iron) implies that the final step in heme synthesis, iron incorporation into protoporphyrin IX, is defective (fig. S6). This contrasts studies of DBA and del(5q) MDS stage I cells where heme is higher than in normal controls (Fig. 3B). Consistent with normal to low heme content, the levels of $A L A S 2, F L V C R, H M O X 1 / 2$, and globin mRNAs in all stages at culture day 10 were equivalent to normals and did not resemble DBA and del(5q) MDS.

We also cultured marrow cells from three MDS patients with del(5q) plus other complex cytogenetic abnormalities and/or myelofibrosis. Their complete blood counts showed pancytopenia and not macrocytic anemia, and marrow culture outcomes were indistinguishable from the patient with RCMD (fig. S6).

\section{DISCUSSION}

Tight synchronization of heme and globin synthesis is needed because of the rapid kinetics of erythropoiesis, which is unparalleled at other tissue sites. A normal adult makes $2.4 \times 10^{6}$ red blood cells per second; each cell contains $270 \times 10^{6}$ hemoglobin molecules; each molecule contains two a-globin and two $\beta$-globin chains plus four heme moieties. Thus, we make and coordinate 2.6 quadrillion heme and 2.6 quadrillion globin molecules per second. Marrow erythropoiesis can also expand 5 to $10 \times$ to physiologically respond to stress. Heme-globin coordination needs to be quick, efficient, yet sufficiently malleable to adjust to pathological and physiological stresses.

Given these rapid kinetics, CFU-E/early proerythroblasts are particularly vulnerable to heme toxicity because this is the time during red blood cell differentiation when heme synthesis intensifies but globin expression is low. Previous studies in cats $(22,23)$, mice $(20,24)$, and human cell lines (21) suggest that the heme exporter FLVCR is critical at this stage and functions as a safety valve, exporting excess heme. In mice lacking FLVCR, heme accumulates, leading to high cytoplasmic ROS, increased CFU-E/early proerythroblast cell death, and macrocytic anemia (24).

Here, we hypothesize and then show that DBA and $\operatorname{del}(5 \mathrm{q})$ MDS have a related pathogenesis. In both disorders, there is haploinsufficiency of ribosomal proteins, poor ribosome assembly, and insufficient ribosome numbers or function to quickly initiate globin translation. This results in delayed globin production, excessive heme in CFU-E/early proerythroblasts, and increased cytoplasmic ROS. Erythroid cells capable of adjusting their heme content by decreased heme synthesis (less ALAS2) or increased heme export (more FLVCR) preferentially survive and then fully mature, whereas other CFU-E/early proerythroblasts die. Different abilities to either genetically or epigenetically regulate intracellular heme might also explain why DBA patients and family members with the same ribosomal gene mutation are variably anemic.

Macrocytosis (high mean cell volume) and the normal (or elevated) mean hemoglobin concentrations characterize DBA and del(5q) MDS (and the anemia of Flvcr-deleted mice). We suspect that this reflects the continued stimulation of globin production by high levels of 
heme. The day 13 to 17 data of Fig. 4(A to $\mathrm{C}$ and $\mathrm{H}$ to J) and the data in fig. S4 and (31) are consistent with this concept and kinetics.

How excess heme induces cell death is less certain, but this likely involves both ferroptosis and apoptosis. Ferroptosis is a newly described, poorly understood process that is initiated by cytoplasmic ROS and involves lipid peroxidation (25-27). Excess heme (by decreasing BACH1 and HRI activity) or through excess ROS production could also trigger aberrant transcription or translation (32-34).

Recent data regarding ferroptosis (35) also provide a link between previous studies implicating P53 activation in the pathogenesis of DBA and del(5q) MDS anemia $(4-6,11)$ and our observations implicating excess heme. Specifically, P53 transcriptionally represses SLC7A11, which encodes a cystine-glutamate transport protein (fig. S7). This inhibits cystine uptake and decreases the synthesis of glutathione, the primary cellular antioxidant, thus sensitizing cells to ferroptosis (35). Because SLC7A11 is a transcriptional target of BACH1, and uniquely is activated (not repressed) by BACH1 (36), excess heme should not only generate ROS (32) but also further decrease SLC7A11. Consistent with this, stage I cells from DBA patient 1 expressed $69.6 \%$ less $S L C 7 A 11$ mRNA than control stage I cells. An implication of these pathophysiological connections is that lenalidomide [which stabilizes MDM2 and decreases P53 (37)] and therapies slowing heme synthesis should be synergistic (fig. S7). Decreasing heme synthesis would also synergize with therapies such as erythropoietin and prednisone, because these interventions act earlier in erythropoiesis (38).

There are two other findings from our experiments. First, erythroid differentiation in cultures of marrow from patients with DBA, del(5q) MDS, RARS, and RCMD excellently phenocopies erythroid differentiation in vivo. Thus, this can be used as a reliable platform for future experimentation and preclinical studies. Second, the observation that epigenetic differences between cells can lead to their preferential death or survival during differentiation (Fig. 3, C and D) has broad implications. In other studies of biological regulation, querying late cells (those preferentially surviving), and not just those at the affected stage, could provide important insights.

Although the use of primary patient material is a strength and uniqueness of our studies, there are important limitations. The numbers of independent experiments are small; variable marrow cell growth could reflect factors unrelated to DBA or MDS; and at times, there was insufficient material for the planned studies. However, despite the genetic heterogeneity implicit in human samples, the outcomes of our DBA and del(5q) MDS studies were similar to each other and different from controls. Also, DBA patient 1 who is haploin-sufficient for RPS19 (the most prevalent genetic defect in DBA) donated marrow specifically for research. As her marrow cells were used in all experiments, we could reliably integrate results.

There are several murine models of DBA $(39,40)$, but unfortunately, the hematopoietic phenotypes incompletely capture DBA. For example, mice heterozygous for $R p s 19$ have normal erythropoiesis, even when stressed, and mice lacking Rps19 die before birth. The most commonly used DBA model is doxycycline-induced short hairpin RNA knockdown of Rps19(41) where the extent of anemia depends on the intensity of doxycycline exposure. 
Low-level chronic doxycycline exposure results in an extremely mild anemia and macrocytosis, yet pronounced changes in lymphocyte, granulocyte, and platelet numbers. Still, it seems likely that studies in this model coupled with studies in a murine model of del(5q) MDS where an interval of DNA including Rps14 is haploinsufficient and/or studies in a recently reported murine model of $R p 111$ haploinsufficiency (42) could complement our studies in primary human cells to provide additional preclinical data and new physiological insights. As one example, murine studies have confirmed the relationship between P53 activation and anemia seen in DBA and del(5q) MDS patient-derived marrow cultures (4, $11,41-43)$.

The prime observation of our studies is that early red blood cells in DBA and del(5q) MDS patients die when heme exceeds globin. Our findings that impairing heme synthesis directly, by restricting iron availability or by facilitating heme export through FLVCR, improves erythropoiesis provide a rationale for new therapies. Others have reported that the anemia of low-risk MDS patients, including patients lacking del(5q), can improve with iron chelation $(44,45)$, and this improvement has been attributed to improved BFU-E growth (46). Many distinct genetic mutations are seen in low-risk MDS, yet anemia is the most prominent clinical phenotype. Because any mutation or event that slows protein transcription or translation might impede brisk protein, and hence brisk globin production, it seems possible that heme toxicity contributes to the anemia of MDS patients without del $(5 q)$ and that these clinical interventions could be broadly applicable.

\section{MATERIALS AND METHODS}

\section{Research objectives}

The purpose of these studies is to determine why red blood cell production fails in DBA and del(5q) MDS and, specifically, to test the hypothesis that the macrocytic anemia results from heme toxicity.

\section{Experimental design and statistical analyses}

The study involves validating a culture system for erythropoiesis in vitro by showing that it faithfully reproduces erythropoiesis in vivo, and using this approach to study the erythroid differentiation of marrow cells from three patients with DBA, six patients with del(5q) MDS, and relevant controls, noting the time-wise coordination of heme with globin synthesis as erythroid cells mature, the heme content of early erythroid progenitors, and its consequences. Student's $t$ test is used for statistical analyses and to generate $P$ values.

\section{Patient characteristics and culture techniques}

Marrow aspirates were obtained with institutional review board approval and written consent. Clinical characteristics of the three DBA patients, six del(5q) MDS patients, and five other MDS patients are in the Supplementary Materials (labeled as Patient information) and in table S1, which also indicates how each sample was used. To study differentiation in vitro, mononuclear cells were cultured using the three-step protocol of Giarratana et al. (28) except that erythropoietin was $2 \mathrm{IU} / \mathrm{ml}$ and step 1 was extended from 7 to 10 days. At day $10,>98 \%$ of cells were $\mathrm{CD} 71^{+} \mathrm{CD} 3^{-} \mathrm{CD} 11 \mathrm{~b}^{-} \mathrm{CD} 19^{-}$and were thus committed to 
erythropoiesis. Succinylacetone was obtained from Sigma-Aldrich and was added at a concentration of $10 \mu \mathrm{M}$ (29) at culture day 0 in some studies; purified rabbit apo-hemopexin was a gift from A. Smith (University of Missouri-Kansas City, Kansas City, MO) and was added at concentrations of 1.5 or $15 \mu \mathrm{M}(30)$ at culture day 2 in some studies.

Flow cytometry

Anti-CD36, anti-CD235 (GlyA), and anti-CD71 combined with anti-CD3, anti-CD11b, and anti-CD19 for lineage specificity (BD Pharmingen) were used to monitor erythropoiesis. Apoptosis was assessed by Annexin V-FITC Apoptosis Detection Kit and propidium iodide staining (BD Pharmingen). Subset analyses and sorting were performed on FACSCanto II and FACSAria III flow cytometers (BD Biosciences) equipped with FACSDiva software, and subsequent analysis was performed with FlowJo software (Tree Star Inc.). Although CD71 and CD235 expression traditionally define discrete stages of erythroid differentiation, CD71 marks TfR1 and thus would be a variable in studies of cellular iron uptake and hemeglobin coordination. Therefore, we tracked CD36, a stable, well-characterized surrogate (Fig. 1A) (12, 13). Cytoplasmic ROS was quantitated by CM-H2DCFDA, and mitochondrial ROS was quantitated by MitoSOX Red (Invitrogen/Molecular Probes). Isotype control and gating strategies are shown in fig. S8.

\section{Quantitative RT-PCR}

Multiplex quantitative RT-PCR was performed using iScript First-Strand Synthesis and iQ5 Multicolor Real-Time PCR Detection Systems (Bio-Rad). Human complementary DNA clones (OriGene) were used as standards. Probes were labeled with FAM, HEX, and Cy5 (Integrated DNA Technologies). Results were expressed as copy numbers as normalized by $\beta$-actin in $50 \mathrm{ng}$ of total RNA. All forward and reverse primer pairs spanned introns (table S2).

\section{Heme and protein determination}

Cellular heme content was measured using oxalate methods (47). Western blots of cell lysates were probed with monoclonal antibodies to a-globin, $\beta$-globin (Abcam), and ALAS2 (Santa Cruz Biotechnology). Anti- $\beta$-actin (Sigma-Aldrich) was used to assess protein loading (fig. S9).

\section{Supplementary Material}

Refer to Web version on PubMed Central for supplementary material.

\section{Acknowledgments}

We would like to thank our patients, especially DBA patient 1 , for their support of these studies. We would also like to thank K. Igarashi for the human $\beta$-globin gene promoter plasmid used in fig. S2, A. Smith for providing hemopexin (Fig. 4G), and R. Doty for help with the hemopexin assay.

Funding: This work was supported by R01 HL031823 from the NIH and A96257 from the Taub Foundation (to J.L.A.). 


\section{REFERENCES AND NOTES}

1. Landowski M, O’Donohue MF, Buros C, Ghazvinian R, Montel-Lehry N, Vlachos A, Sieff CA, Newburger PE, Niewiadomska E, Matysiak M, Glader B, Atsidaftos E, Lipton JM, Beggs AH, Gleizes PE, Gazda HT. Novel deletion of RPL15 identified by array-comparative genomic hybridization in Diamond-Blackfan anemia. Hum Genet. 2013; 132:1265-1274. [PubMed: 23812780]

2. Horos R, von Lindern M. Molecular mechanisms of pathology and treatment in Diamond Blackfan Anaemia. Br J Haematol. 2012; 159:514-527. [PubMed: 23016900]

3. Fumagalli S, Di Cara A, Neb-Gulati A, Natt F, Schwemberger S, Hall J, Babcock GF, Bernardi R, Pandolfi PP, Thomas G. Absence of nucleolar disruption after impairment of 40S ribosome biogenesis reveals an rpL11-translation-dependent mechanism of p53 induction. Nat Cell Biol. 2009; 11:501-508. [PubMed: 19287375]

4. Dutt S, Narla A, Lin K, Mullally A, Abayasekara N, Megerdichian C, Wilson FH, Currie T, KhannaGupta A, Berliner N, Kutok JL, Ebert BL. Haploinsufficiency for ribosomal protein genes causes selective activation of p53 in human erythroid progenitor cells. Blood. 2011; 117:2567-2576. [PubMed: 21068437]

5. Ellis SR. Nucleolar stress in Diamond Blackfan anemia pathophysiology. Biochim Biophys Acta. 2014; 1842:765-768. [PubMed: 24412987]

6. Jaako P, Debnath S, Olsson K, Zhang Y, Flygare J, Lindström MS, Bryder D, Karlsson S. Disruption of the 5S RNP-Mdm2 interaction significantly improves the erythroid defect in a mouse model for Diamond-Blackfan anemia. Leukemia. 2015; 29:2221-2229. [PubMed: 25987256]

7. Horos R, Ijspeert H, Pospisilova D, Sendtner R, Andrieu-Soler C, Taskesen E, Nieradka A, Cmejla R, Sendtner M, Touw IP, von Lindern M. Ribosomal deficiencies in Diamond-Blackfan anemia impair translation of transcripts essential for differentiation of murine and human erythroblasts. Blood. 2012; 119:262-272. [PubMed: 22058113]

8. Rey MA, Duffy SP, Brown JK, Kennedy JA, Dick JE, Dror Y, Tailor CS. Enhanced alternative splicing of the FLVCR1 gene in Diamond Blackfan anemia disrupts FLVCR1 expression and function that are critical for erythropoiesis. Haematologica. 2008; 93:1617-1626. [PubMed: 18815190]

9. Ludwig LS, Gazda HT, Eng JC, Eichhorn SW, Thiru P, Ghazvinian R, George TI, Gotlib JR, Beggs AH, Sieff CA, Lodish HF, Lander ES, Sankaran VG. Altered translation of GATA1 in DiamondBlackfan anemia. Nat Med. 2014; 20:748-753. [PubMed: 24952648]

10. Ebert BL, Pretz J, Bosco J, Chang CY, Tamayo P, Galili N, Raza A, Root DE, Attar E, Ellis SR, Golub TR. Identification of RPS14 as a $5 \mathrm{q}^{-}$syndrome gene by RNA interference screen. Nature. 2008; 451:335-339. [PubMed: 18202658]

11. Barlow JL, Drynan LF, Hewett DR, Holmes LR, Lorenzo-Abalde S, Lane AL, Jolin HE, Pannell R, Middleton AJ, Wong SH, Warren AJ, Wainscoat JS, Boultwood J, McKenzie ANJ. A p53dependent mechanism underlies macrocytic anemia in a mouse model of human 5q- syndrome. Nat Med. 2010; 16:59-66. [PubMed: 19966810]

12. Hu J, Liu J, Xue F, Halverson G, Reid M, Guo A, Chen L, Raza A, Galili N, Jaffray J, Lane J, Chasis JA, Taylor N, Mohandas N, An X. Isolation and functional characterization of human erythroblasts at distinct stages: Implications for understanding of normal and disordered erythropoiesis in vivo. Blood. 2013; 121:3246-3253. [PubMed: 23422750]

13. Li J, Hale J, Bhagia P, Xue F, Chen L, Jaffray J, Yan H, Lane J, Gallagher PG, Mohandas N, Liu J, An X. Isolation and transcriptome analyses of human erythroid progenitors: BFU-E and CFU-E. Blood. 2014; 124:3636-3645. [PubMed: 25339359]

14. Hentze MW, Muckenthaler MU, Galy B, Camaschella C. Two to tango: Regulation of mammalian iron metabolism. Cell. 2010; 142:24-38. [PubMed: 20603012]

15. Suzuki H, Tashiro S, Hira S, Sun J, Yamazaki C, Zenke Y, Ikeda-Saito M, Yoshida M, Igarashi K. Heme regulates gene expression by triggering Crm1-dependent nuclear export of Bach1. EMBO J. 2004; 23:2544-2553. [PubMed: 15175654]

16. Tahara T, Sun J, Nakanishi K, Yamamoto M, Mori H, Saito T, Fujita H, Igarashi K, Taketani S. Heme positively regulates the expression of $\beta$-globin at the locus control region via the 
transcriptional factor Bach1 in erythroid cells. J Biol Chem. 2004; 279:5480-5487. [PubMed: 14660636]

17. Han AP, Yu C, Lu L, Fujiwara Y, Browne C, Chin G, Fleming M, Leboulch P, Orkin SH, Chen JJ. Heme-regulated eIF2a kinase (HRI) is required for translational regulation and survival of erythroid precursors in iron deficiency. EMBO J. 2001; 20:6909-6918. [PubMed: 11726526]

18. Ajioka RS, Phillips JD, Kushner JP. Biosynthesis of heme in mammals. Biochim Biophys Acta. 2006; 1763:723-736. [PubMed: 16839620]

19. Dailey HA, Meissner PN. Erythroid heme biosynthesis and its disorders. Cold Spring Harb Perspect Med. 2013; 3:a011676. [PubMed: 23471474]

20. Keel SB, Doty RT, Yang Z, Quigley JG, Chen J, Knoblaugh S, Kingsley PD, De Domenico I, Vaughn MB, Kaplan J, Palis J, Abkowitz JL. A heme export protein is required for red blood cell differentiation and iron homeostasis. Science. 2008; 319:825-828. [PubMed: 18258918]

21. Quigley JG, Yang Z, Worthington MT, Phillips JD, Sabo KM, Sabath DE, Berg CL, Sassa S, Wood BL, Abkowitz JL. Identification of a human heme exporter that is essential for erythropoiesis. Cell. 2004; 118:757-766. [PubMed: 15369674]

22. Testa NG, Onions D, Jarrett O, Frassoni F, Eliason JF. Haemopoietic colony formation (BFU-E, GM-CFC) during the development of pure red cell hypoplasia induced in the cat by feline leukaemia virus. Leuk Res. 1983; 7:103-116. [PubMed: 6304428]

23. Abkowitz JL. Retrovirus-induced feline pure red cell aplasia: Pathogenesis and response to suramin. Blood. 1991; 77:1442-1451. [PubMed: 1849031]

24. Doty RT, Phelps SR, Shadle C, Sanchez-Bonilla M, Keel SB, Abkowitz JL. Coordinate expression of heme and globin is essential for effective erythropoiesis. J Clin Invest. 2015; 125:4681-4691. [PubMed: 26551679]

25. Yang WS, SriRamaratnam R, Welsch ME, Shimada K, Skouta R, Viswanathan VS, Cheah JH, Clemons PA, Shamji AF, Clish CB, Brown LM, Girotti AW, Cornish VW, Schreiber SL, Stockwell BR. Regulation of ferroptotic cancer cell death by GPX4. Cell. 2014; 156:317-331. [PubMed: 24439385]

26. Dixon SJ, Lemberg KM, Lamprecht MR, Skouta R, Zaitsev EM, Gleason CE, Patel DN, Bauer AJ, Cantley AM, Yang WS, Morrison B III, Stockwell BR. Ferroptosis: An iron-dependent form of nonapoptotic cell death. Cell. 2012; 149:1060-1072. [PubMed: 22632970]

27. Friedmann Angeli JP, Schneider M, Proneth B, Tyurina YY, Tyurin VA, Hammond VJ, Herbach N, Aichler M, Walch A, Eggenhofer E, Basavarajappa D, Rådmark O, Kobayashi S, Seibt T, Beck H, Neff F, Esposito I, Wanke R, Förster H, Yefremova O, Heinrichmeyer M, Bornkamm GW, Geissler EK, Thomas SB, Stockwell BR, O'Donnell VB, Kagan VE, Schick JA, Conrad M. Inactivation of the ferroptosis regulator Gpx4 triggers acute renal failure in mice. Nat Cell Biol. 2014; 16:11801191. [PubMed: 25402683]

28. Giarratana MC, Rouard H, Dumont A, Kiger L, Safeukui I, Le Pennec PY, Francois S, Trugnan G, Peyrard T, Marie T, Jolly S, Hebert N, Mazurier C, Mario N, Harmand L, Lapillonne H, Devaux JY, Douay L. Proof of principle for transfusion of in vitro-generated red blood cells. Blood. 2011; 118:5071-5079. [PubMed: 21885599]

29. Ponka P, Wilczynska A, Schulman HM. Iron utilization in rabbit reticulocytes. A study using succinylacetone as an inhibitor or heme synthesis. Biochim Biophys Acta. 1982; 720:96-105. [PubMed: 7059619]

30. Yang Z, Philips JD, Doty RT, Giraudi P, Ostrow JD, Tiribelli C, Smith A, Abkowitz JL. Kinetics and specificity of feline leukemia virus subgroup $\mathrm{C}$ receptor (FLVCR) export function and its dependence on hemopexin. J Biol Chem. 2010; 285:28874-28882. [PubMed: 20610401]

31. Nathan DG, Piomelli S, Gardner FH. The synthesis of heme and globin in the maturing human erythroid cell. J Clin Invest. 1961; 40:940-946. [PubMed: 13727909]

32. Ghaffari S. Oxidative stress in the regulation of normal and neoplastic hematopoiesis. Antioxid Redox Signal. 2008; 10:1923-1940. [PubMed: 18707226]

33. Igarashi K, Watanabe-Matsui M. Wearing red for signaling: The heme-bach axis in heme metabolism, oxidative stress response and iron immunology. Tohoku J Exp Med. 2014; 232:229_ 253. [PubMed: 24681888] 
34. Chen JJ. Translational control by heme-regulated eIF2a kinase during erythropoiesis. Curr Opin Hematol. 2014; 21:172-178. [PubMed: 24714526]

35. Jiang L, Kon N, Li T, Wang SJ, Su T, Hibshoosh H, Baer R, Gu W. Ferroptosis as a p53-mediated activity during tumour suppression. Nature. 2015; 520:57-62. [PubMed: 25799988]

36. Warnatz HJ, Schmidt D, Manke T, Piccini I, Sultan M, Borodina T, Balzereit D, Wruck W, Soldatov A, Vingron M, Lehrach H, Yaspo ML. The BTB and CNC homology 1 (BACH1) target genes are involved in the oxidative stress response and in control of the cell cycle. J Biol Chem. 2011; 286:23521-23532. [PubMed: 21555518]

37. Wei S, Chen X, McGraw K, Zhang L, Komrokji R, Clark J, Caceres G, Billingsley D, Sokol L, Lancet J, Fortenbery N, Zhou J, Eksioglu EA, Sallman D, Wang H, Epling-Burnette PK, Djeu J, Sekeres M, Maciejewski JP, List A. Lenalidomide promotes p53 degradation by inhibiting MDM2 auto-ubiquitination in myelodysplastic syndrome with chromosome 5q deletion. Oncogene. 2013; 32:1110-1120. [PubMed: 22525275]

38. Narla A, Dutt S, McAuley JR, Al-Shahrour F, Hurst S, McConkey M, Neuberg D, Ebert BL. Dexamethasone and lenalidomide have distinct functional effects on erythropoiesis. Blood. 2011; 118:2296-2304. [PubMed: 21527522]

39. McGowan KA, Mason PJ. Animal models of Diamond Blackfan anemia. Semin Hematol. 2011; 48:106-116. [PubMed: 21435507]

40. Keel SB, Phelps S, Sabo KM, O’Leary MN, Kirn-Safran CB, Abkowitz JL. Establishing Rps6 hemizygous mice as a model for studying how ribosomal protein haploinsufficiency impairs erythropoiesis. Exp Hematol. 2012; 40:290-294. [PubMed: 22198155]

41. Jaako P, Flygare J, Olsson K, Quere R, Ehinger M, Henson A, Ellis S, Schambach A, Baum C, Richter J, Larsson J, Bryder D, Karlsson S. Mice with ribosomal protein S19 deficiency develop bone marrow failure and symptoms like patients with Diamond-Blackfan anemia. Blood. 2011; 118:6087-6096. [PubMed: 21989989]

42. Morgado-Palacin L, Varetti G, Llanos S, Gómez-López G, Martinez D, Serrano M. Partial loss of Rp111 in adult mice recapitulates Diamond-Blackfan Anemia and promotes lymphomagenesis. Cell Rep. 2015; 13:712-722. [PubMed: 26489471]

43. McGowan KA, Pang WW, Bhardwaj R, Perez MG, Pluvinage JV, Glader BE, Malek R, Mendrysa SM, Weissman IL, Park CY, Barsh GS. Reduced ribosomal protein gene dosage and p53 activation in low-risk myelodysplastic syndrome. Blood. 2011; 118:3622-3633. [PubMed: 21788341]

44. List AF, Baer MR, Steensma DP, Raza A, Esposito J, Martinez-Lopez N, Paley C, Feigert J, Besa E. Deferasirox reduces serum ferritin and labile plasma iron in RBC transfusion-dependent patients with myelodysplastic syndrome. J Clin Oncol. 2012; 30:2134-2139. [PubMed: 22547607]

45. Delforge M, Selleslag D, Beguin Y, Triffet A, Mineur P, Theunissen K, Graux C, Trullemans F, Boulet D, Van Eygen K, Noens L, Van Steenweghen S, Lemmens J, Pierre P, D'Hondt R, Ferrant A, Deeren D, Van De Velde A, Wynendaele W, André M, De Bock R, Efira A, Breems D, Deweweire A, Geldhof K, Pluymers W, Harrington A, MacDonald K, Abraham I, Ravoet C. Adequate iron chelation therapy for at least six months improves survival in transfusion-dependent patients with lower risk myelodysplastic syndromes. Leuk Res. 2014; 38:557-563. [PubMed: 24661630]

46. Hartmann J, Braulke F, Sinzig U, Wulf G, Maas JH, Konietschke F, Haase D. Iron overload impairs proliferation of erythroid progenitors cells (BFU-E) from patients with myelodysplastic syndromes. Leuk Res. 2013; 37:327-332. [PubMed: 23259989]

47. Sinclair, PR.; Gorman, N.; Jacobs, JM. Measurement of heme concentration. In: Maines, MD., editor. Current Protocols in Toxicology. Vol. chap. 8.3. Wiley; New York: 2001. p. 8.3.1-8.3.7.

48. Abkowitz JL, Schaison G, Boulad F, Brown DL, Buchanan GR, Johnson CA, Murray JC, Sabo KM. Response of Diamond-Blackfan anemia to metoclopramide: Evidence for a role for prolactin in erythropoiesis. Blood. 2002; 100:2687-2691. [PubMed: 12351372] 
A

Marrow Blood

BFU-E CFU-E Proerythroblast Reticulocyte Red cell

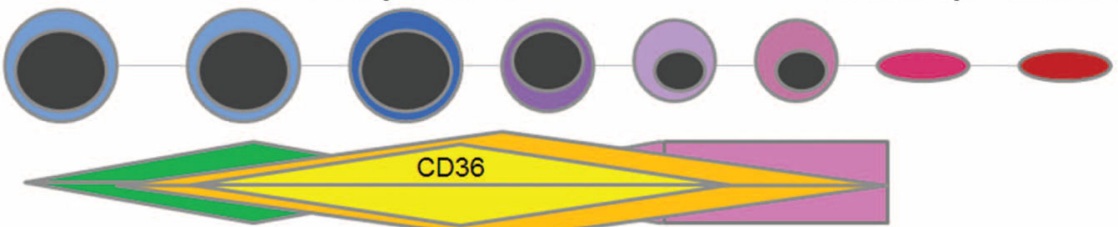

Erythropoietin Transferrin receptor 1 (CD71) GlyA (CD235)

receptor

Iron binds IRPs and induces ALAS2 translation (the 5'UTR of ALAS2

mRNA contains an IRE).

Heme synthesis intensifies.

Heme induces globin transcription and translation by inhibiting repressors $\mathrm{BACH} 1$ and heme-regulated elF $2 \alpha$ kinase $(\mathrm{HRI})$.

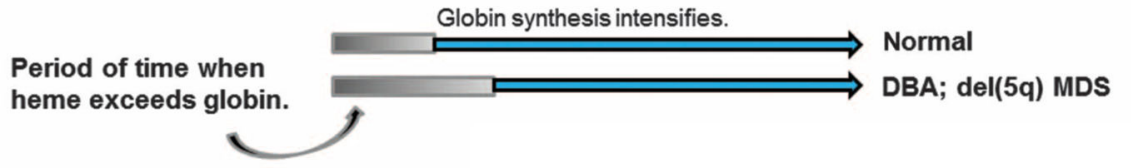

B

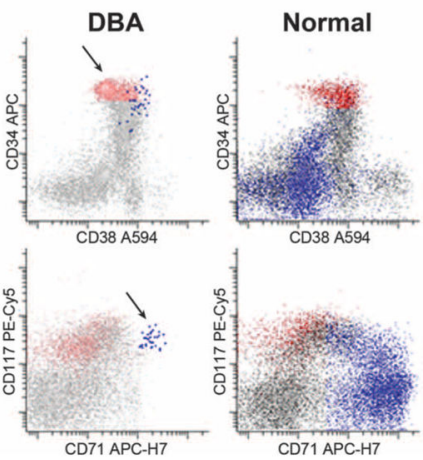

Fig. 1. Heme and globin during normal erythropoiesis, hypothesis, and DBA patient 1's marrow aspirate

(A) Heme and globin synthesis during normal erythropoiesis. When erythroid progenitor cells mature, cell surface proteins are sequentially expressed, beginning with the erythropoietin receptor (green). The presence or absence of these markers can thus be used to determine the stage of differentiation (see text for details). CFU-E and early proerythroblasts up-regulate TfR expression (CD71; orange), allowing the uptake of transferrin-bound iron. CD36 (yellow) is also up-regulated at this stage $(12,13)$, whereas glycophorin A (GlyA; pink) is expressed later in red blood cell maturation. Iron induces heme synthesis (red arrow) because the $5^{\prime}$ untranslated region ( $5^{\prime}$ UTR) of $A L A S 2$, the initial and rate-limiting step of the heme synthetic pathway, contains an iron-responsive element (IRE). Heme then induces globin transcription and translation by binding the inhibitors BACH1 $(15,16)$ and eIF2a kinase (17), respectively, so as soon as heme is present, globin synthesis (blue arrow) begins. FLVCR serves as a safety valve to export excess heme and protect erythroid cells from heme toxicities during the period of time (gray bar) that heme synthesis is robust, but globin levels are low $(20,21)$. Hypothesis: In DBA and del(5q) MDS, globin synthesis initiates slowly because of insufficient ribosome availability or function, whereas heme synthesis proceeds normally. The capacity of FLVCR 
to export heme from early erythroid precursors is exceeded. This results in toxic quantities of intracellular free heme, CFU-E/proerythroblast cell death, a low reticulocyte count, and a severe macrocytic anemia. IRPs, iron regulatory proteins. (B) Flow cytometric analysis of a marrow aspirate from DBA patient 1 . Progenitors were identified by intermediate CD45 expression and low side scatter. There is a relative expansion of CD34 $/$ CD38 low progenitors ( $61 \%$ of bright $\mathrm{CD} 34^{+}$; red) that lack immunophenotypic evidence of lineage commitment (top arrow) in comparison to normal marrow ( $24 \%$ of bright $\mathrm{CD} 34^{+}$; red). In addition, erythroid precursors (high CD71; blue) are almost completely absent and the few present are arrested at the proerythroblast stage [still express CD117 (c-kit)] (bottom arrow) in comparison to normal marrow where most CD71-positive cells lack CD117 expression. These data suggest that DBA cells die at or just before the proerythroblast stage when they first express CD71 (the TfR), import iron, and begin heme synthesis. APC, allophycocyanin; PE, phycoerythrin. 


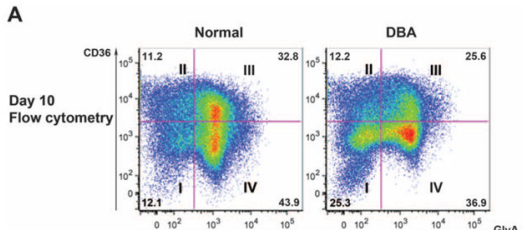

C

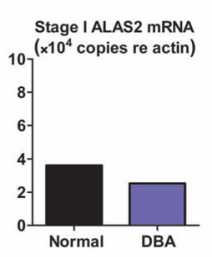

$\mathrm{F}$

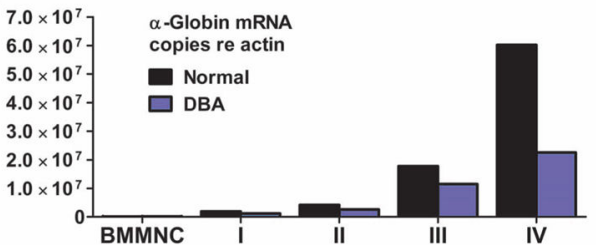
Stage I heme content
5 (ng per $10^{4}$ cells)

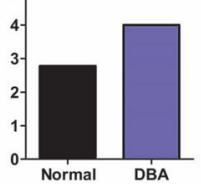

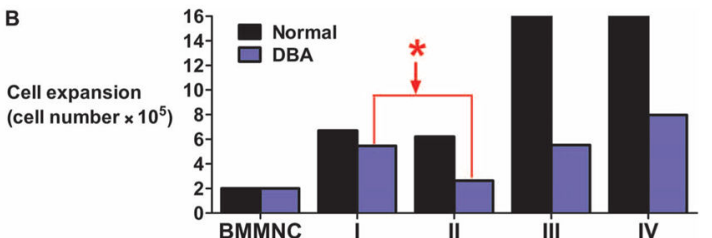
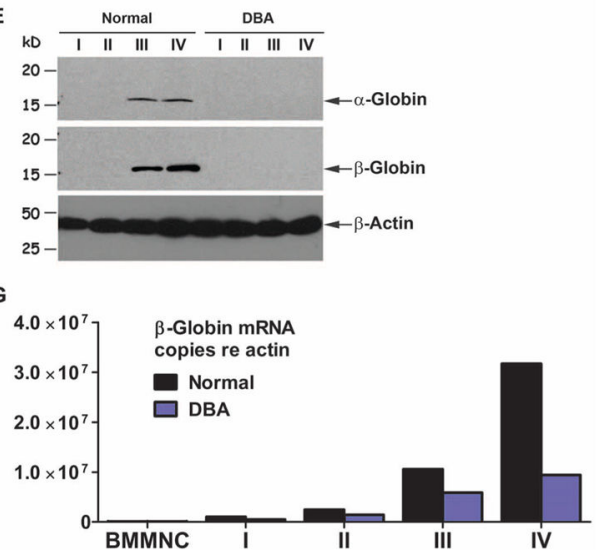

Fig. 2. Representative studies of marrow cells at culture day 10

Marrow culture studies confirm that DBA erythropoiesis fails by the early proerythroblast stage. (A) As shown in this study of DBA patient 2 and a concurrent normal control, there is a relative increase $(25.3 \%$ versus $12.1 \%$ ) in the percentage of DBA versus normal cells in stage I and a relative decrease in later stages (III and IV). (B) Similarly, the absolute numbers of DBA cells fall significantly between stages I and II. Although the number of DBA cells in stage II is low, these numbers progressively increase in stages III and IV, suggesting that those few DBA cells, which reach stage II, can expand in number and mature to stages III and IV. Flow percentages were multiplied by the total number of cells in culture and then expressed as that number of cells derived from $2 \times 10^{5}$ bone marrow mononuclear cells (BMMNCs) placed in culture on day 0. Similar patterns were seen in cultures of marrow cells from the two other DBA patients and the six del(5q) MDS patients. In DBA, globin synthesis initiates slowly and heme accumulates. (C) Heme synthesis begins normally as indicated by the levels of ALAS2, the first and rate-limiting step in heme synthesis. (D) However, there is substantially more heme in stage I DBA cells than in stage I control cells $\left(4.01 \pm 0.11\right.$ versus $2.78 \pm 0.02 \mathrm{ng}$ per $10^{4}$ cells) in this study of DBA patient 1 . (E) Although the amount of heme in her stage I cells is high, the amount of globin protein is sufficiently low that it is not detectable by Western blot. (F and $\mathbf{G}$ ) Her a-globin and $\beta$ globin mRNAs are also low; however, they are 35 to $65 \%$ of control values and are thus not as low as globin protein. $a$-Globin and $\beta$-globin mRNA levels were comparably decreased in stage I to IV cells from the two other DBA patients and three del(5q) MDS patients at culture day 10, but quantities of marrow cells were not sufficient for Western blot analyses. 


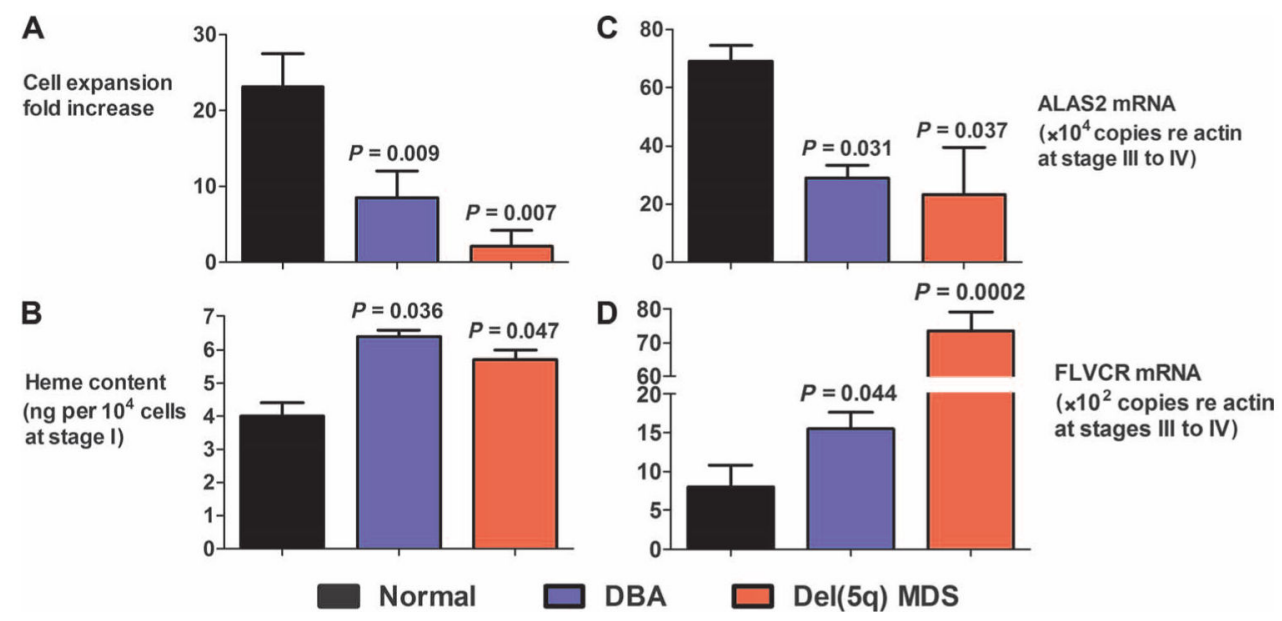

Fig. 3. Cumulative data from DBA and $\operatorname{del}(5 q)$ MDS day 10 marrow cultures

Erythroid differentiation fails from heme toxicity. (A) In cumulative studies, DBA patients' $(n=3)$ erythroid cells expand poorly $(n=3 ; P=0.009, t$ test $)$, and cell death occurs at or before stage II as shown in Fig. 2B. (B) Stage I cells contain increased heme ( $n=3 ; P=$ $0.036, t$ test). (C) The DBA cells in stages III and IV express significantly lower $A L A S 2$ than stage III and IV control cells. In contrast, stage I DBA cells express equal amounts of $A L A S 2$ as control cells $\left(2.53 \pm 0.72\right.$ versus $3.61 \times 10^{4} \pm 0.93 \times 10^{4}$ copies; $n=3 ; P=0.29, t$ test). (D) Similarly, the DBA cells in stages III and IV express significantly higher FLVCR than stage III and IV control cells. In contrast, stage I DBA cells express equal amounts of FLVCR mRNA as control cells ( $3.67 \pm 0.10$ versus $2.73 \times 10^{3} \pm 0.57 \times 10^{3}$ copies; $n=3 ; P$ $=0.29, t$ test). These data suggest that stage I DBA cells able to down-regulate their heme content by decreasing heme synthesis (lower ALAS2) or increasing heme export (higher FLVCR) survive, whereas stage I cells with excessive heme die. The studies of marrow cells from five del(5q) MDS patients resemble the studies in the three DBA patients. There is poor cell expansion at culture day 10 (A), significantly lower $A L A S 2$ mRNA in stage III and IV cells (C), and extremely high FLVCR mRNA in stage III and IV cells (D). There was also increased heme in the stage I cells of the two del(5q) MDS patients from whom sufficient marrow was available for this assay (B). 
A

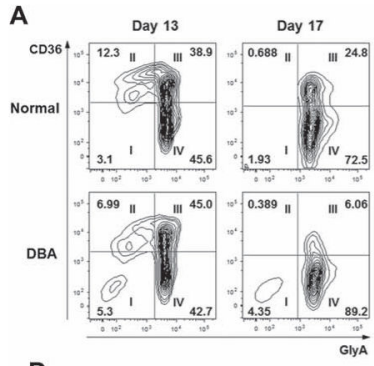

D

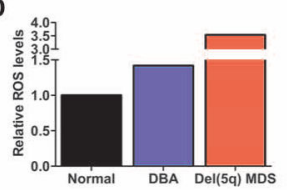

$\mathbf{F}$

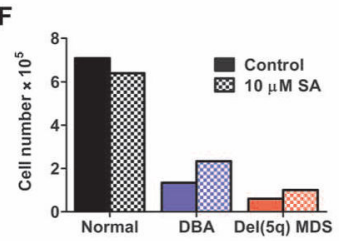

H

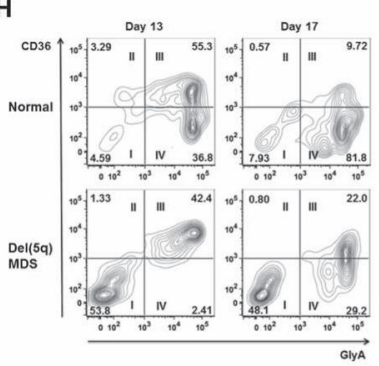

B

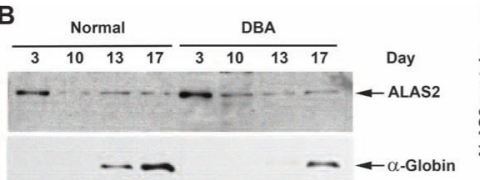

$-20-\beta-$-Globin

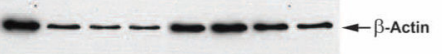

E

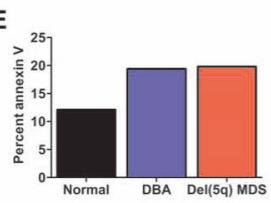

G

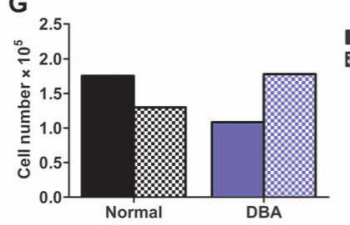

I

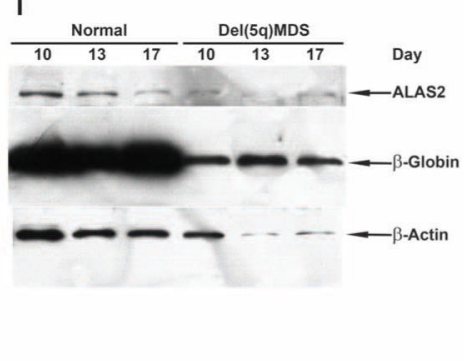

C

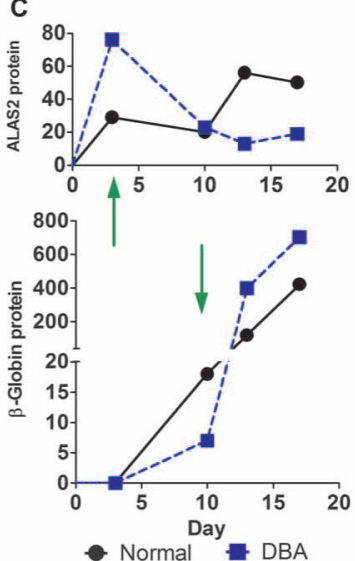

Control 国 $1.51 \mu \mathrm{M} \mathrm{HPX}$
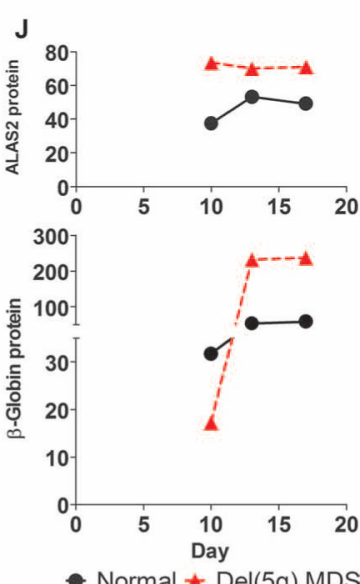

- Normal $₫ \operatorname{Del}(5 q)$ MDS

Fig. 4. Longitudinal studies of erythroid maturation

Sequential observations of marrow cultures confirm the hypothesis diagrammed in fig. S3. (A) The flow cytometric patterns of day 13 and 17 DBA patient 1's cells are equivalent to controls, confirming that the late erythroid maturation of DBA cells proceeds normally. (B and C) ALAS2 protein and globin protein levels at culture days 3, 10, 13, and 17. Western blot analyses are shown in (B), and their quantifications are shown in (C). At culture day 3 (green arrow), the amount of ALAS2 in DBA patient 1's cells is comparable to (actually higher than) control. However, globin production initiates slowly (second green arrow) and is much lower than control at day 10 , leading to a longer than normal time interval when heme is present but globin is absent or low. We interpret the decrease in ALAS2 protein at culture days 13 and 17 to reflect the preferential survival of DBA cells with less excessive heme, given that increased cell death occurs by day 7 (see text). ALAS2, globin, and FLVCR mRNA data are shown in fig. S4A and are consistent with these findings. (D) At culture day 7, increased numbers of DBA cells and del(5q) MDS cells have cytoplasmic ROS (62.8 and $74.1 \%$, respectively, versus $44.7 \%$ of control) and the MFI, representing the quantities of ROS per cell, is also higher $(1.42 \times$ and $3.54 \times$, respectively) than control. When the DBA patient study was repeated, the results were comparable. (E) Increased numbers of DBA cells and del(5q) MDS cells stain positively for annexin V (19.4 and 19.8\%, respectively, versus $12.1 \%$ of control cells). When the DBA patient study was repeated, the results were 
comparable. (F) The erythroid differentiation of DBA and del(5q) MDS cells improves when heme synthesis is slowed. Marrow cells from DBA and del(5q) MDS patients and concurrent controls were grown in the presence or absence of a low concentration of succinylacetone (SA; $10 \mu \mathrm{M})(29)$, a potent and specific competitive inhibitor of the second step of the heme synthetic pathway. Succinylacetone significantly improved erythroid cell expansion in the DBA culture at days 7 and 10, whereas the erythroid cell expansion of control cells mildly decreased. Specifically, the DBA cell expansion at culture day 7 (expressed as number of erythroid cells derived from $2 \times 10^{5}$ BMMNCs placed in culture on day 0 ) increased $74.6 \%$ from $1.34 \times 10^{5}$ to $2.34 \times 10^{5}(n=2 ; P=0.04, t$ test $)$. This increased $95.4 \%$ from $0.99 \times 10^{5}$ to $1.93 \times 10^{5}$ in a second independent study ( $n=2 ; P=0.03, t$ test). Erythroid cell expansion in the del(5q) MDS culture increased $67.7 \%$ from $0.6 \times 10^{5}$ to 1.0 $\times 10^{5}(n=2 ; P=0.03, t$ test $)$. (G) Treatment with hemopexin (HPX) to facilitate heme export through FLVCR. Exposure to $1.5 \mu \mathrm{M}$ hemopexin improved the erythroid cell expansion of the DBA culture by $63.3 \%$ at day $14(n=2 ; P=0.05, t$ test $)$, whereas the erythroid cell expansion in the control culture decreased by $26.1 \%(n=2 ; P=0.10, t$ test $)$. When the study was repeated, the results were comparable. (H to J) Sequential observations of marrow cultures from del(5q) MDS patient 6 also support our hypothesis. The late erythroid maturation of del(5q) MDS cells proceeds equivalently to the concurrent normal control $(\mathrm{H})$. Western blot analyses of ALAS2 protein and globin protein levels (normalized to actin) at culture days 10,13, and 17 are shown in (I) and their quantifications are in (J). ALAS2, globin, and FLVCR mRNA levels are shown in fig. S4B; there were insufficient numbers of cells for studies at culture day 3. The data resemble the DBA patient study (Fig. 4, A to C, and fig. S4A). Heme synthesis initiates normally, but globin synthesis is delayed. 